\title{
Rankings or Absolute Feedback? Investigating Two Feedback Alternatives for Negotiation Agreements in a Gamified Electronic Negotiation Training
}

\author{
Andreas Schmid \\ University of Hohenheim, Germany \\ a_schmid@uni-hohenheim.de
}

\begin{abstract}
The use of game elements in non-game contexts has gained popularity in the education domain to increase students' motivation and engagement. Additionally, these elements provide feedback on students' performance. Rankings are often applied to display performance feedback relative to others despite their potential negative effects, for example due to increased pressure. In this experimental study, we compare two types of gamified electronic negotiation training, each including the game elements levels, badges, and experience points. As the reflection on the negotiation performance is a central activity for negotiation training, we test two feedback alternatives for the negotiation agreements. One group received relative feedback through rankings, and the other group received a non-game and absolute feedback called Pareto graph. Our findings show similar intrinsic motivation and negotiation outcomes, but higher engagement for participants using the Pareto graph. Practitioners and researchers are encouraged to consider non-game feedback elements in their gamification design.
\end{abstract}

\section{Introduction}

Lecturers nowadays often face problems regarding their students' motivation and engagement [25], and as a consequence with students' learning outcomes. Learning tasks compete against distracting and more interesting activities [4]. Therefore, sustaining students' attention, increasing their motivation and engagement, and supporting their learning has become a major challenge in education [9].

Gamification, defined as the use of game elements in non-game contexts [8], has become a popular approach in education to mitigate the previously described problems $[9,15,48]$. Reviews in the education domain predominantly report positive effects of gamification on motivation, engagement, and learning [9, 28, 42]. Gamification has a positive impact on knowledge retention [36] and is expected to improve social and practical skills such as problem-solving, collaboration, and communication [20,36].

One area for practical and social skill development is the field of electronic negotiation (e-negotiation) training. Negotiations are nowadays often conducted via electronic media [47] and one can expect their importance to grow further in times of COVID-19. Therefore, individuals are expected to gain the relevant skills for these negotiations. To facilitate the development of e-negotiation skills, university courses teaching negotiation theory and practice use web-based negotiation support systems (NSSs) [23, 30]. Such an enegotiation training follows Kolb's experiential learning methodology [22], where participants engage in negotiations (the experience) and have to reflect about this experience for effective learning to take place [23]. However, participants after a traditional enegotiation training still settle on inefficient agreements [14], and one reason might be insufficient motivation and engagement to practice and reflect about negotiations [43].

In a prior study, a NSS used in such a training has been enhanced with the game elements levels, badges, experience points and rankings [43]. These elements demonstrated their effectiveness to increase motivation and engagement of participants compared to traditional e-negotiation training [43]. The rankings provide constructive feedback on the quality of the settled agreement supporting the crucial reflections and are expected to incentivise participants to experiment with different negotiation strategies [44]. While interviews confirmed this assumption [43], the use of rankings is sometimes considered as problematic due to potentially negative effects such as social comparison [19], induced competition [40] and in consequence less motivation [16]. Furthermore, in e-negotiations a ranking only provides feedback relative to others and includes no information about possible improvements beyond the first place [43]. 
An alternative feedback visualisation in the field of negotiations is the Pareto graph [51], providing absolute feedback about one's performance. Since in gamification design the synergy of different elements contributing to a motivating and interesting experience matters, this study follows a research stream to identify the best combinations of elements [10]. In particular, we conducted an experiment in which participants in an enegotiation training either received feedback by rankings or feedback through the non-game element Pareto graph, while not manipulating the other game elements. Our first research goal is to investigate the effects of relative and absolute feedback on participants' motivational experiences and their engagement. In consequence, these effects may influence the achieved negotiation outcomes in the training. Prior research has focussed on the effects of a training for subsequent negotiations [30], but not for the training negotiations themselves, which is therefore our second research goal.

The remainder of the paper is structured as follows: First, we describe the application domain of NSSs and e-negotiation training, review the relationship between goals, feedback, and motivation, and describe the two investigated feedback mechanisms afterwards. Next, the hypotheses are derived, followed by the description the methodology, the results, and the discussion. Finally, the paper concludes with a summary, limitations of this study, and implications for researchers and practitioners.

\section{Theoretical Background}

\subsection{Decision Support in E-Negotiations}

For several years, business negotiations are conducted electronically [47]. In a negotiation at least two negotiators deal with interdependent tasks and continually engage in decision-making and communication tasks [2]. E-negotiations differ from face-to-face negotiations for example through missing social cues such as mimics and gestures [23]. Negotiation support systems (NSSs) were developed for e-negotiations with the aim to find agreements of higher quality and to save transaction costs [2]. Therefore, these systems provide the negotiators with communication and decision support [46].

To evaluate offers in complex negotiations with multiple negotiation issues, NSSs provide decision support by means of a utility value [46]. In the preparation phase, the negotiators define their preferences, i.e. they determine their preferred values for all negotiation issues and rank the issues according to their importance. Based on these information and multi-attribute utility theory (MAUT) [33], the NSS computes a utility value between 0 and 100 for each received offer or during the creation of a new offer. An offer with a utility value of 100 perfectly corresponds one's preferences, whereas an offer with a value of 0 does not correspond one's preferences at all. The negotiation ends when one negotiator agrees to accept a received offer or when a negotiator decides to leave the negotiation without an agreement.

The negotiation outcomes are described by their effectiveness (i.e. agreement rate) and the agreements' efficiency [35]. The efficiency of an agreement is usually described by the individual utility, the joint utility (sum of negotiators' individual utilities), and fairness [7]. As both negotiators' preferences may not be perfectly opposing, the joint utility may exceed a value of 100 [7]. The joint utility provides information on whether and to what extent the negotiators have exploited the potential for an integrative agreement (win-win solution). The contract imbalance (the difference between the two individual utilities) provides details about the agreement's fairness [7].

\subsection{Gamified E-Negotiation Training}

NSSs have been used for more than 15 years in university courses to facilitate students' development of e-negotiation skills [23, 30]. An e-negotiation training includes a system training for the NSS being used as well as a training for the development of e-negotiation skills [30]. Such negotiation training employs the experiential learning methodology [22], where participants are having an experience, followed by reflection, abstraction, and generalisation [23]. Therefore, the participation in a negotiation scenario followed by a structured debriefing supporting reflections is essential [23].

However, current forms of e-negotiation training insufficiently facilitate participants' motivation and engagement [43]. Based on motivation theories such as self-determination theory (SDT) [38] and goal-setting theory [26], requirements for a gamified e-negotiation training have been derived [44]. They were successfully realised by integrating game elements in a NSS used in such a training [43]. Repeatable levels are implemented, with each of them representing one negotiation scenario in which participants negotiate with a software agent. These levels become increasingly more challenging by making the negotiation scenario and the NSS used more complex. Experience points and badges award desirable system use. Badges also include difficult negotiation goals to reach. For a more detailed description we refer the interested reader to [43].

Participants in the gamified training have the freedom to decide whether they would like to follow a competitive approach (i.e. maximising own profit) or an 
integrative approach (i.e. maximising joint profit). To facilitate the aforementioned reflections, feedback is required so participants can evaluate whether they reached their goals and settled on a good agreement [44]. In a prior study, utility rankings have been implemented, enabling comparison with others and providing feedback on negotiation agreements [43]. In general, feedback for agreements is expected to incentivise participants to experiment with different negotiation strategies in order to find a better agreement [23, 44]. Higher engagement, i.e. when participants repeat negotiations, improves negotiation skills and outcome efficiency [1, 50]. However, high levels of engagement require motivated participants.

\subsection{The Relation between Goals, Feedback and Motivation}

Goal-setting theory proposes that individuals are motivated to strive towards goals [26]. Furthermore, difficult goals lead to higher effort and performance than low goals [26]. Feedback informs individuals which goals to attain, how they currently perform towards these goals, and what steps to perform next [17]. Therefore, feedback is crucial for learning activities. When learning activities include rapid feedback cycles, learners perceive failure as an essential part of learning and experiment until they succeed [25]. Besides passively receiving feedback e.g. by lecturers, Festinger's theory of social comparison processes postulates an inherent drive in every individual to evaluate one's opinions and abilities [11]. One option to judge one's abilities is the comparison with other individuals. Comparing oneself with others can make individuals aware of their lack of abilities, informs them about their status, and encourages competition [13]. A large discrepancy between one's abilities compared to better individuals leads to a drive upward [11] and results in higher learning outcomes [32].

Depending on the task, individuals may also have the chance to evaluate their abilities to objective absolute standards. Festinger's theory maintains that individuals will not compare their abilities with others when objective standards are available [8]. This claim has been supported, showing that absolute feedback is more effective than comparative feedback [31].

Researchers have further argued that the relationship between high goals and high performance is moderated by an individual's goal commitment, i.e. the determination to reach a goal [21]. If there is no goal commitment, a goal cannot have a motivational effect. The goals of an individual influence its goal commitment, because goals are chosen based on one's assumption that the goal can be reached [26]. Feedback enables them to set reasonable goals and once they have been reached to strive upwards to higher goals [17]. Goal commitment can be induced by feedback itself, e.g. by competition or rewards [17].

Feedback has also direct effects on individuals' motivation. According to self-determination theory (SDT) [38], the satisfaction of the basic psychological needs for autonomy, competence, and relatedness facilitate intrinsic motivation, which is the desirable type of motivation for learning. If feedback is perceived as controlling, autonomy is undermined and intrinsic motivation will be diminished [38]. Autonomysupportive feedback facilitates intrinsic motivation [38]. Comparative feedback induces competition and can cause feelings of pressure [19], which diminishes one's perceived autonomy and in consequence intrinsic motivation [37]. In gamification research, the use of achievement elements providing inherent feedback to the users such as badges, rankings and levels has been shown to satisfy the needs for competence and autonomy [41, 52].

\subsection{Feedback for Negotiation Agreements}

Gamified interventions often use rankings to provide relative feedback in comparison with others for simple performance metrics [9, 24, 28]. In an e-negotiation training participants' achieved individual utilities, joint utilities, and the contract imbalance can be ranked. Such a ranking allows the participants to evaluate their agreement and compare it with others negotiating the same scenario. In a prior study [43], the rankings including these three metrics were available once a participant has settled on an agreement with the software agent (see figure 1). Participants can switch between the three rankings via the tabs.

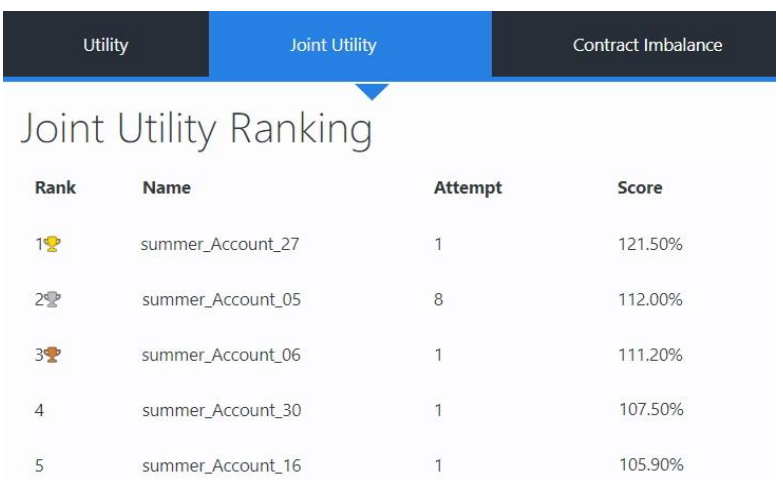

Figure 1. Screenshot of an anonymised joint utility ranking.

Interviews with participants in a prior study revealed that the rankings were rather perceived as informational performance feedback than as a competition among 
them [43]. Nevertheless, the use of rankings can be problematic, as they induce social comparison resulting in pressure on participants [19], can decrease motivation [16] and participants may not like competition at all [45]. Furthermore, such a ranking does not provide information about the best possible negotiation agreement. Therefore, the use of utility rankings in enegotiation training may not be the best choice to provide feedback on the agreements.

The use of an alternative feedback mechanism to improve learning has already been suggested [43]: Participants may receive absolute feedback for their negotiation agreement through the Pareto graph [51]. The graph depicts one's agreement in a diagram (see big blue dot in figure 2), where the axes represent the individual utility values of both negotiation partners. The red points represent Pareto-optimal agreements and are often called Pareto frontier, i.e. agreements in which none of the negotiators can improve his/her result without the other one being worse off [51]. Participants can evaluate their agreement to an objective standard, i.e. whether the agreement is Pareto-optimal and whether they achieved a fair and integrative agreement. Therefore, the Pareto graph provides absolute feedback.

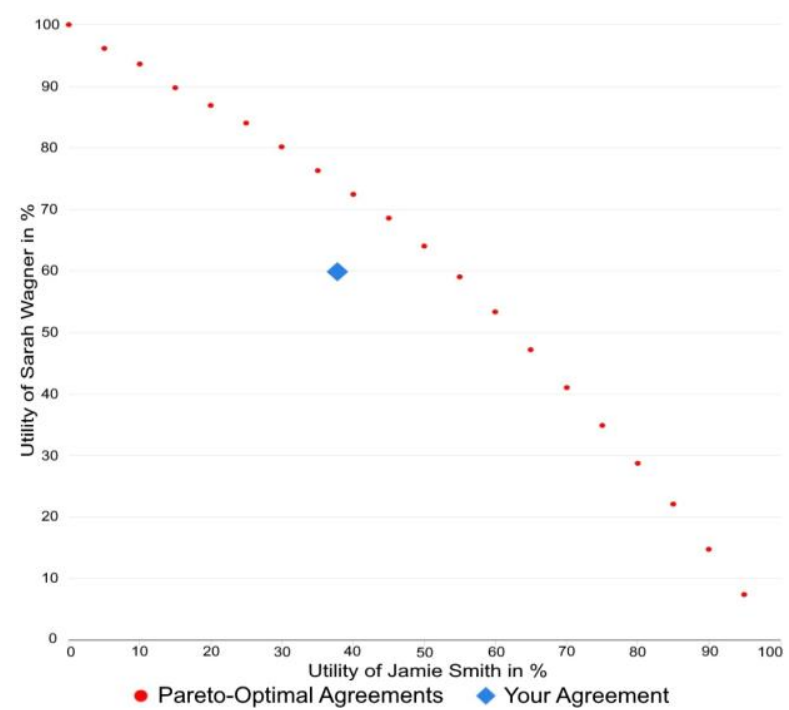

Figure 2. Screenshot of the Pareto graph with individual utilities (0 to 100) as axes.

\section{Hypotheses}

In this study, we compare the two previously described feedback mechanisms for negotiation agreements and derive the following hypotheses from the literature. First, the use of comparative feedback in form of the rankings provides transparency about participants' performances and can make participants aware of their lack of abilities compared to others [13].
Rankings induce social comparison and competition $[13,19]$, which in turn increase perceived pressure [19, 37], even for well-performing individuals [19]. Since users of the Pareto graph compare their performance with objective standards and without competition, we propose:

H1: Users of the rankings will perceive higher pressure than users of the Pareto graph.

Without feedback negotiation training participants experience uncertainty about how well they performed and whether they exploited the negotiation potential. The type of feedback could influence beliefs about one's e-negotiation competence. Mekler et al. [29] found no effect of rankings on competence, whereas another study found a negative effect on competence [3]. It is hypothesised that only for participants at the top of a ranking feelings of competence can arise [40]. The Pareto graph provides feedback about individual performance compared to an objective standard. In another study including a task with uncertain outcomes, the use of absolute feedback has stronger effects on beliefs about ones abilities than comparative feedback [31]. Given the potentially negative effects of relative feedback, we hypothesise:

H2: Users of the Pareto graph perceive themselves as more competent to conduct e-negotiations than users of the rankings.

The satisfaction of the basic psychological needs for autonomy, relatedness, and competence facilitates intrinsic motivation [38]. Rankings were found to reduce relatedness [3]. In another study, the use of rankings did not impact intrinsic motivation [29]. However, when participants receive feedback through a ranking and have the choice to repeat and undo errors (similar to our gamified e-negotiation training design), participants experience autonomy and higher intrinsic motivation [32]. Furthermore, intrinsic motivation is negatively affected by pressure [37]. On the one hand, rankings could increase pressure $(\mathrm{H} 1)$, might not be beneficial for perceived competence $(\mathrm{H} 2)$, and reduce relatedness. On the other hand, they could increase autonomy. Since the majority of factors influencing intrinsic motivation is supposed to have negative effects for rankings, we conclude:

H3: Users of the rankings are less intrinsically motivated compared to users of the Pareto graph.

Using rankings to provide feedback, individuals set different goals to work for: Some may strive for a top position, others for a place in the midfield and others focus on not ending up in last place [24]. Therefore, the goal commitment to reach good agreements in the training using rankings might highly differ. Clear and 
difficult goals are more effective than nonspecific goals [17], and the Pareto frontier provides such a clear goal to work for [14]. Consequently, we propose:

H4: Users of the Pareto graph are more committed to reach good agreements than users of the rankings.

Rankings have been shown to raise engagement levels of individuals compared to control groups [3, 29]. However, individuals only tend to engage in a task again when they face a high discrepancy to the top position, whereas individuals at the top of a ranking are satisfied with their performance [32]. When people are provided with absolute feedback, they might still find potential for self-improvement. In a brain-training game absolute feedback increased future game play compared to relative feedback [5]. In the Pareto graph, the distance between one's agreement and the Pareto frontier (see figure 2) outlines clear improvements for the participants. It might further incentivise them to experiment with other negotiation approaches. Therefore, we hypothesise:

H5: Users of the Pareto graph show higher engagement compared to users of the rankings.

The results of negotiations are assessed by their effectiveness (i.e. agreement rate) and efficiency (i.e. quality of agreements) [35]. According to the so called negotiation dilemma, these two dimensions are conflicting objectives, since striving for a better agreement reduces the chances of reaching an agreement at all [34]. Prior research has not studied the effects of motivation and engagement on outcomes in training negotiations before. In general, participants with a low integrative agreement and a large distance to the Pareto frontier will seek to improve their agreement [14]. In this training, participants have the chance to repeatedly experiment with different approaches without being judged for failure [10]. On the one hand, experimenting with different negotiation approaches is a key element of e-negotiation training [23]. On the other hand, negotiation experience is an important factor for more efficient agreements [27]. Further, practicing negotiations enables participants to logroll more effectively, thus resulting in more efficient agreements $[1,50]$. Therefore, and in-line with H5, we propose:

H6: Users of the Pareto graph (a) achieve more efficient agreements and (b) negotiate less effective than users of the rankings.

\section{Research Methodology}

To test the hypotheses an experiment was conducted in May 2020 with 69 undergraduate students participating in an online course at a German university.
The students were enrolled in management, economics, or information systems. As part of the course, students were taught negotiation theory and case studies, followed by the negotiation experiment described in the following section.

\subsection{Procedure}

The experiment used the gamified e-negotiation training described in section 2.2, where the participants learned to use the NSS and to negotiate electronically. The training prepared them for a five-day international e-negotiation. Participants received fixed credit points for their participation in the training and the surveys, regardless of their performance in the training. They further received credit points depending on their performance in the international e-negotiation, but we will focus only on the training in the following.

Participants were randomly assigned to one of the two training groups receiving feedback on their negotiation agreements either by the utility rankings or the Pareto graph. In a first online survey demographic data was assessed. Within a timeframe of four days, the participants had to complete the training. Estimated expenditure for the training are 90 minutes and participants had to complete the first three of five levels. Participants could practice further until the international e-negotiation started. The utility rankings (see figure 1) or the Pareto graph (see figure 2) were shown for the first time after level two, where the utility values were explained. Above both elements a textual description provided explanations about the graph or metrics respectively. After the training, participants had to fill in a second online survey measuring the variables described in the next section.

\subsection{Data Collection \& Analysis}

After the training, participants' motivational experiences were measured using the Intrinsic Motivation Inventory (IMI) by Ryan et al. [39], an established measurement in gamification research [48] based on the SDT. Five items measured participants' intrinsic motivation (e.g. "I thought the training was very interesting") and four items their competence for conducting e-negotiations (e.g. "I think I am pretty good at negotiating electronically"). Additionally, the IMI includes a subscale for pressure, from which three items were adopted (e.g. "I felt pressured while doing the training").

For relatedness, the three items used in [41] have been adapted (e.g. "I felt socially related with others during the training"). Autonomy with regard to decision freedom was measured with three items [41] (e.g. 
"During the training I could make my own decisions"). Four items assessed participants' goal commitment [18, 24] (e.g. "I was strongly committed to reach good negotiation agreements in the training").

All items were measured using a 7-point Likert scale, ranging from 1 (strongly disagree) to 7 (strongly agree). One item for competence and one for goal commitment indicated standardised factor loadings below 0.4. Since they are below recommended thresholds [49] and the items could be interpreted as an evaluation of the software agent used instead of measuring the intended latent variable, it was decided to remove these items. The variables, the final item count, and Cronbach's alpha are shown in table 1, with each variable exceeding the typically recommended threshold for Cronbach's alpha of 0.7 [12].

Table 1. Variables and Cronbach's alpha.

\begin{tabular}{lcc}
\hline Variable & Items & Cronbach's $\alpha$ \\
\hline Intrinsic motivation & 5 & .88 \\
\hline Pressure & 3 & .76 \\
\hline E-negotiation competence & 3 & .81 \\
\hline Autonomy (decisions) & 3 & .75 \\
\hline Relatedness & 3 & .82 \\
\hline Goal commitment & 3 & .86 \\
\hline
\end{tabular}

In addition to the subjective measures, we complement our analysis with objective measures for participants' engagement and the negotiation outcomes. Participants had the option to practice by conducting additional negotiations in the system, i.e. by proceeding further than level three or repeating a certain level. As a measure of voluntary engagement, each additional concluded negotiation is counted [43] and we analyse up to which level participants proceeded. Furthermore, the negotiations with the software agent provide a comparable data set. For each level, negotiation effectiveness is operationalised by the agreement rate [30]. Negotiation agreement efficiency is measured using individual utility, joint utility, and contract imbalance [7].

Participants were excluded from the analysis if they had not answered the surveys or did not participate in the training. Two participants were excluded due to prior experiences with the system. In total, 53 participants remained for statistical analysis, which was performed using IBM SPSS Statistics 26.

\section{Results}

After filtering the data, 27 participants using the Pareto graph and 26 participants using the utility rankings remain for the analysis. Gender is almost equally distributed among the groups (rankings: 13 females; Pareto graph: 12 females). On average, the students are 22.18 years old $(\mathrm{SD}=3.07)$. To account for the small sample size and non-normal distribution of the data, non-parametric independent samples MannWhitney $\mathrm{U}$ test will be used to compare the two groups [12]. The medians, means, standard deviations, and Mann-Whitney $U$ test statistics for all survey and engagement variables are shown in table 2 .

$\mathrm{H} 1$ postulated that users of the rankings perceive higher pressure. Pressure values are below the average of the scale and higher for the ranking group than for the Pareto graph group, but this difference is statistically not significant $(\mathrm{p}=.17$, one-sided). Thus, H1 cannot be supported.

$\mathrm{H} 2$ assumed that users of the Pareto graph perceive themselves as more competent to conduct e-negotiations than users of the rankings. There is indeed a tendency that the Pareto graph users perceive themselves as more competent than ranking users. However, this difference is close to but still not statistically significant $(\mathrm{p}=.056$, one-sided). Consequently, $\mathrm{H} 2$ cannot be supported.

Furthermore, H3 assumed that ranking users are less intrinsically motivated than Pareto graph users. Intrinsic motivation is in general quite high and higher for Pareto graph users than for ranking users, but no significant effect is found ( $p=.23$, one-sided). Relatedness as one factor for intrinsic motivation is below the scale's average and slightly worse in the ranking group, but no significant effect is found $(\mathrm{p}=.30)$. Autonomy in regard to decision freedom as another factor is quite high in both groups. The ranking group reports higher autonomy than the Pareto graph group, but again no significant effect is found $(p=.39)$. Since there are neither significant differences for the basic psychological needs nor for intrinsic motivation, H3 has to be rejected.

H4 predicted higher goal commitment of participants using the Pareto graph to reach good negotiation agreements. Goal commitment for the Pareto graph group is in fact higher than in the ranking group. However, there is no statistically significant difference, so $\mathrm{H} 4$ is rejected $(\mathrm{p}=.075$, one-sided).

H5 assumed higher engagement in the Pareto graph group. Participants were required to complete at least level 3 and could proceed further. Analysing the additional negotiations conducted and the level reached, the Pareto graph group reveals clearly higher engagement. Pareto graph users perform more additional negotiations. There is a statistically significant difference $(\mathrm{p}=.014$, one-sided $)$ and a medium effect $(r=-0.30)$. Pareto graph users also proceed further within the levels compared to the ranking users. This also results in a medium effect $(\mathrm{r}=-0.34)$ and a statistically significant difference ( $\mathrm{p}=.007$, one-sided). Thus, H5 can be confirmed. 
Table 2. Descriptive and test statistics for survey and engagement variables.

\begin{tabular}{|l|c|c|c|c|c|c|c|c|}
\cline { 2 - 9 } \multicolumn{1}{c|}{} & \multicolumn{2}{c|}{ Utility ranking } & \multicolumn{2}{c|}{ Pareto graph } & \multicolumn{3}{c|}{ Mann-Whitney U test } \\
\hline Variables & Median & Mean (SD) & Median & Mean (SD) & U & $\mathrm{z}$ & $\mathrm{p}$ & $\mathrm{r}$ \\
\hline Pressure & 3.83 & $3.68(1.09)$ & 3.33 & $3.40(1.00)$ & 298 & -0.95 & $.17^{1}$ & -.13 \\
\hline E-negotiation competence & 5.00 & $4.79(0.78)$ & 5.33 & $5.15(0.85)$ & 217.5 & -1.44 & $.056^{1}$ & -.22 \\
\hline Intrinsic motivation & 5.40 & $5.28(0.92)$ & 5.60 & $5.42(0.97)$ & 309 & -0.75 & $.23^{1}$ & -.10 \\
\hline Relatedness & 3.33 & $3.27(1.23)$ & 3.67 & $3.56(1.12)$ & 293 & -0.95 & .30 & -.14 \\
\hline Autonomy (decisions) & 5.33 & $5.32(0.72)$ & 5.00 & $5.19(0.77)$ & 303.5 & -0.85 & .39 & -.12 \\
\hline Goal Commitment & 5.13 & $5.26(1.00)$ & 5.67 & $5.65(0.88)$ & 217.5 & -1.44 & $.075^{1}$ & -.20 \\
\hline Additional negotiations* & 1.50 & $2.69(3.78)$ & 5.00 & $5.67(7.80)$ & 228 & -2.22 & $.014^{1}$ & -.30 \\
\hline Level reached** & 3.00 & $3.62(0.85)$ & 5.00 & $4.26(0.94)$ & 226 & -2.45 & $0.007^{1}$ & -.34 \\
\hline
\end{tabular}

Notes: $* p<.05, * * p<.01 .{ }^{1}$ denotes one-sided $p$-value.

Table 3. Negotiation outcomes for the levels showing agreement rates, achieved individual utilities (IU), joint utilities (JU) and contract imbalance (Cl).

\begin{tabular}{|l|c|c|c|}
\hline Level & Variables & Utility ranking & Pareto graph \\
\hline Level 2 & Participants & 26 & 27 \\
& Agreement rate & $81.41 \%$ & $74.22 \%$ \\
& Mean avg. IU (SD), Mean max. IU* & $50.94(5.63), 51.13$ & $53.96(6.01), 54.28$ \\
& Mean avg. JU (SD), Mean max. JU & $121.97(3.82), 121.97$ & $122.01(3.80), 122.25$ \\
& Mean avg. CI (SD), Mean max. CI & $20.18(11.23), 20.57$ & $15.52(10.01), 16.54$ \\
\hline Level 3 & Participants & 26 & 27 \\
& Agreement rate & $85.44 \%$ & $83.51 \%$ \\
& Mean avg. IU (SD), Mean max. IU & $59.57(8.76), 60.67$ & $55.78(10.44), 56.72$ \\
& Mean avg. JU (SD), Mean max. JU & $122.94(6.27), 123.82$ & $120.72(6.88), 121.07$ \\
& Mean avg. CI (SD), Mean max. CI* & $11.62(8.56), 12.61$ & $15.89(10.20), 17.46$ \\
\hline Level 4 & Participants & 10 & 18 \\
& Agreement rate & $58.34 \%$ & $55.00 \%$ \\
& Mean avg. IU (SD), Mean max. IU & $50.46(3.76), 51.12$ & $49.65(6.09), 48.87$ \\
& Mean avg. JU (SD), Mean max. JU & $112.05(3.43), 112.35$ & $113.83(5.49), 114.12$ \\
& Mean avg. CI (SD), Mean max. CI & $11.13(4.32), 12.22$ & $14.53(8.77), 14.79$ \\
\hline
\end{tabular}

Notes: $* p<.05$.

H6 postulated (a) more efficient agreements but also (b) fewer effectiveness for users of the Pareto graph. Table 3 shows the agreement rates revealing the effectiveness and the individual utilities, joint utilities, and contract imbalance for the efficiency of the agreements. For the latter three variables, the average values achieved for all performed negotiations of a participant are given as well as the extreme (max) scores that a participant has achieved within a level. Level 1 did not include decision support and the feedback yet and is therefore not analysed as well as level 5, which only 6 participants of the ranking group completed. For all variables only two statistically significant differences are found. First, Pareto graph users' individual utilities in their best level 2 negotiation ( $M=54.28)$ differs from the best result of the ranking users $(\mathrm{M}=51.13), \mathrm{U}=236$, $\mathrm{z}=-2.05, \mathrm{p}=.04$. Second, in level 3 Pareto graph users' extreme score for contract imbalance is higher $(\mathrm{M}=$ 17.46) than for ranking users $(\mathrm{M}=12.61)$, indicating that they achieved unfairer agreements $(\mathrm{U}=239.5$, $\mathrm{z}=-1.19, \mathrm{p}=.047)$. Since individual utilities in other levels are slightly higher for ranking users and the other variables provide an inconclusive picture, we conclude that H6a and H6b cannot be confirmed.

\section{Discussion}

Although rankings increase pressure [19], the reported pressure in this study is quite low and there are no significant differences between the groups. One reason might be that there was no plain condition with rankings only, but the rankings were presented in combination with other game elements. Another reason might stem from the perceptions of the rankings, which previously were found to provide rather informational feedback than induce competition among the participants [43]. Feedback perceived as informational can enhance intrinsic motivation [6].

Intrinsic motivation does not differ between the two groups, although a tendency exists that users of the Pareto graph are a little more intrinsically motivated. 
Absolute feedback exerts stronger effects on affective reactions than comparative feedback [31]. However, the choice to repeat improves motivation when a ranking is present [32]. Further analysing the basic psychological needs facilitating intrinsic motivation [38], no significant differences are found. Relatedness is lower in the ranking group and therefore in line with prior research [3]. Autonomy in regard to decision freedom is slightly higher for the participants in the ranking group, which might be related to the choice of the users for which position in the ranking they want to strive for [24]. There is however an insignificant tendency that users of the Pareto graph perceive themselves as more competent than the ranking users. The distance between one's agreement and the objective standard of the Pareto frontier might be a more effective evaluation of an agreement than the distance between one's position and the top position in a ranking.

The use of the Pareto graph also results in a nonsignificant but still higher goal commitment compared to the ranking users. On the one hand, the Pareto frontier provides a clear goal to work for, and the graph's visualisation clearly outlines possible improvements. On the other hand, rankings provide an opportunity for users to set their own goals, which might be a top position in the ranking but might also result in goals such as not ending up in last place [24].

The strongest and statistically significant effect of the feedback provided is found for participants' engagement. Participants using the Pareto graph conducted more voluntary negotiations than participants using the ranking. The majority of the Pareto graph users was further motivated to proceed up to the fifth level. In the context of serious games, the provision of absolute feedback also increased future game play compared to relative feedback [5]. Furthermore, the Pareto graph clearly shows areas for possible improvements, which could motivate participants to improve their agreement and try out different negotiation approaches. For rankings however, participants at the top position are usually satisfied with their performance [32]. This could explain the large discrepancy regarding participants' engagement between the two groups.

The differences regarding engagement and goal commitment are not mirrored in the negotiation outcomes during the training. A key element in enegotiation training is the experimentation with different negotiation approaches [23], and as such sometimes worse agreements for approaches that turn out to be unsuccessful are possible. Nevertheless, prior research has shown that repeating negotiation scenarios improves negotiation skills [1,50]. Given the selfreported competence for e-negotiations and the engagement results, we assume that users of the Pareto graph gained more e-negotiation skills.

\section{Conclusion \& Outlook}

In the present study, we analysed the effects of two elements providing essential feedback for the agreements in a gamified e-negotiation training. Feedback was provided either by comparing one's agreements with others in the utility rankings, or through the Pareto graph providing absolute feedback compared to objective standards. In summary, this study provides some interesting insights on how the modification of one feedback element in a holistic gamification design can result in different outcomes. Regarding the first research goal, the study provides partial evidence for Festinger's claim that absolute feedback is more influential than relative feedback [11]. This influence manifests in significantly higher engagement. No significant differences were found for self-reported motivational experiences. Negotiation outcomes investigated as the second research goal were not affected, thus showing that experimentation with different negotiation approaches in such a training is important [23].

This study includes some limitations. First, the sample size is relatively small and future research may be needed to validate the findings. Due to the sample size, we could not analyse potentially moderating effects between the variables. Second, although participants received credit points independent from their answers given in the surveys, we cannot completely rule out a social desirability bias. Last, the effect on negotiation outcomes might be limited due to the strategy pursued by the software agent in these negotiations and by the negotiation cases themselves.

Finally, we recommend that the usage of rankings in a gamification design should be considered carefully. For a motivating experience, individuals should be given the option to undo errors [32] as in this study. Nonetheless, individuals may not like the induced competition at all [45]. When different feedback alternatives are available, the provision of absolute feedback should be preferred [31]. This study reveals that the use of a non-game feedback element results in a motivational experience too. We encourage researchers and gamification designers to look beyond the typically implemented elements such as points, badges, and rankings and consider the use of domain-specific and non-game feedback elements.

In the context of this study, we might analyse the negotiation approaches applied in detail, i.e. whether they differed and which approaches were used. Furthermore, an analysis of negotiations conducted after 
the training could show whether there are effects on actual negotiation competence. The relationships and potentially mediating effects between the variables could be analysed in a larger study. An analysis of personality traits or player types could further reveal, whether all participants benefit from absolute feedback, or whether the provision of both types of feedback leaving the choice which of them to use to the participants - exerts greater effects.

\section{References}

[1] Bazerman, M.H., T. Magliozzi, and M.A. Neale, "Integrative bargaining in a competitive market", Organizational Behavior and Human Decision Processes, 35(3), 1985, pp. 294-313.

[2] Bichler, M., G.E. Kersten, and S. Strecker, "Towards a structured design of electronic negotiations", Group Decision and Negotiation, 12(4), 2003, pp. 311-335.

[3] Bräuer, P. and A. Mazarakis, "Badges or a leaderboard? How to gamify an augmented reality warehouse setting", in Proceedings of the 3rd International GamiFIN Conference, Levi, Finland, April 8-10, 2019, pp. 229-240.

[4] Buckley, P. and E. Doyle, "Individualising gamification: An investigation of the impact of learning styles and personality traits on the efficacy of gamification using a prediction market", Computers \& Education, 106, 2017, pp. $43-55$.

[5] Burgers, C., A. Eden, M.D. van Engelenburg, and S. Buningh, "How feedback boosts motivation and play in a brain-training game", Computers in Human Behavior, 48, 2015, pp. 94-103.

[6] Deci, E.L., R. Koestner, and R.M. Ryan, "A Meta-Analytic Review of Experiments Examining the Effects of Extrinsic Rewards on Intrinsic Motivation", Psychological Bulletin, 125(6), 1999, pp. 627-668.

[7] Delaney, M.M., A. Foroughi, and W.C. Perkins, "An empirical study of the efficacy of a computerized negotiation support system (NSS)", Decision Support Systems, 20(3), 1997, pp. 185-197.

[8] Deterding, S., D. Dixon, R. Khaled, and L. Nacke, "From game design elements to gamefulness: defining gamification", in Proceedings of the 15th International Academic MindTrek Conference: Envisioning Future Media Environments, Tampere, Finland, ACM: New York, NY, 2011, pp. 9-15.

[9] Dichev, C. and D. Dicheva, "Gamifying education: what is known, what is believed and what remains uncertain: a critical review", International Journal of Educational Technology in Higher Education, 14(1), 2017, pp. 1-36.

[10] Dicheva, D., K. Irwin, and C. Dichev, "Exploring Learners Experience of Gamified Practicing: For Learning or for Fun?", International Journal of Serious Games, 6(3), 2019, pp. 5-21.
[11] Festinger, L., "A Theory of Social Comparison Processes", Human Relations, 7(2), 1954, pp. 117-140.

[12] Field, A., Discovering statistics using IBM SPSS statistics, 5th edn., SAGE, Los Angeles, London, New Delhi, Singapore, Washington DC, Melbourne, 2018.

[13] Garcia, S.M., A. Tor, and R. Gonzalez, "Ranks and Rivals: A Theory of Competition", Personality \& Social Psychology Bulletin, 32(7), 2006, pp. 970-982.

[14] Gettinger, J., M. Filzmoser, and S.T. Koeszegi, "Why can't we settle again? Analysis of factors that influence agreement prospects in the post-settlement phase", Journal of Business Economics, 86(4), 2016, pp. 413-440.

[15] Hamari, J., J. Koivisto, and H. Sarsa, "Does Gamification Work? - A Literature Review of Empirical Studies on Gamification", in Proceedings of the 47th Hawaii International Conference on System Sciences (HICSS), Waikoloa, HI, January 6-9, 2014, pp. 3025-3034.

[16] Hanus, M.D. and J. Fox, "Assessing the effects of gamification in the classroom: A longitudinal study on intrinsic motivation, social comparison, satisfaction, effort, and academic performance", Computers \& Education, 80, 2015, pp. 152-161.

[17] Hattie, J. and H. Timperley, "The Power of Feedback", Review of Educational Research, 77(1), 2007, pp. 81-112.

[18] Hollenbeck, J.R., H.J. Klein, A.M. O'Leary, and P.M. Wright, "Investigation of the Construct Validity of a SelfReport Measure of Goal Commitment", Journal of Applied Psychology, 74(6), 1989, pp. 951-956.

[19] Huschens, M., F. Rothlauf, and R. Rothe, "On the Role of Social Comparison Processes in Gamified Work Situations", in Proceedings of the 52nd Hawaii International Conference on System Sciences (HICSS), Wailea, HI, January 8-11, 2019 , pp. 1446-1455.

[20] Kapp, K.M., The gamification of learning and instruction: Game-based methods and strategies for training and education, Pfeiffer, San Francisco, Calif., 2012.

[21] Klein, H.J., M.J. Wesson, J.R. Hollenbeck, and B.J. Alge, "Goal Commitment and the Goal-Setting Process: Conceptual Clarification and Empirical Synthesis", Journal of Applied Psychology, 84(6), 1999, pp. 885-896.

[22] Kolb, D.A., Experiential learning: Experience as the source of learning and development, Prentice-Hall, Englewood Cliffs, NJ, 1984.

[23] Köszegi, S. and G. Kersten, "On-line/Off-line: Joint Negotiation Teaching in Montreal and Vienna", Group Decision and Negotiation, 12(4), 2003, pp. 337-345.

[24] Landers, R.N., K.N. Bauer, and R.C. Callan, "Gamification of task performance with leaderboards: A goal setting experiment", Computers in Human Behavior, 71, 2017, pp. 508-515.

[25] Lee, J.J. and J. Hammer, "Gamification in Education: What, How, Why Bother?", Academic Exchange Quarterley, 15(2), 2011, pp. 146-151. 
[26] Locke, E.A. and G.P. Latham, "Building a Practically Useful Theory of Goal Setting and Task Motivation: A 35Year Odyssey", American Psychologist, 57(9), 2002, pp. 705717.

[27] Loewenstein, J. and L.L. Thompson, "Learning to Negotiate: Novice and Experienced Negotiators" in L.L Thompson (ed.), Negotiation theory and research, Psychology Press: New York, 2006, pp. 77-97.

[28] Majuri, J., J. Koivisto, and J. Hamari, "Gamification of education and learning: A review of empirical literature", in Proceedings of the 2nd International GamiFIN Conference, Pori, Finland, May 21-23, 2018, pp. 11-19.

[29] Mekler, E.D., F. Brühlmann, A.N. Tuch, and K. Opwis, "Towards understanding the effects of individual gamification elements on intrinsic motivation and performance", Computers in Human Behavior, 71, 2017, pp. 525-534.

[30] Melzer, P. and M. Schoop, "The Effects of Personalised Negotiation Training on Learning and Performance in Electronic Negotiations", Group Decision and Negotiation, 25(6), 2016, pp. 1189-1210.

[31] Moore, D.A. and W.M.P. Klein, "Use of absolute and comparative performance feedback in absolute and comparative judgments and decisions", Organizational Behavior and Human Decision Processes, 107(1), 2008, pp. 60-74.

[32] Nebel, S., M. Beege, S. Schneider, and G.D. Rey, "The higher the score, the higher the learning outcome? Heterogeneous impacts of leaderboards and choice within educational videogames", Computers in Human Behavior, 65, 2016, pp. 391-401.

[33] Neumann, J. von and O. Morgenstern, Theory of games and economic behavior, 60th edn., Princeton University Press, Princeton, 2007.

[34] Pruitt, D.G., Negotiation Behavior, Academic Press, New York, NY, 1981.

[35] Pruitt, D.G. and P.J. Carnevale, Negotiation in social conflict, Open Univ. Press, Maidenhead, 1993.

[36] Putz, L.-M., F. Hofbauer, and H. Treiblmaier, "Can gamification help to improve education? Findings from a longitudinal study", Computers in Human Behavior, 110, 2020 .

[37] Reeve, J. and E.L. Deci, "Elements of the Competitive Situation that Affect Intrinsic Motivation", Personality \& Social Psychology Bulletin, 22(1), 1996, pp. 24-33.

[38] Ryan, R.M. and E.L. Deci, "Self-Determination Theory and the Facilitation of Intrinsic Motivation, Social Development, and Well-Being", American Psychologist, 55(1), 2000, pp. 68-78.

[39] Ryan, R.M., V. Mims, and R. Koestner, "Relation of reward contingency and interpersonal context to intrinsic motivation: A review and test using cognitive evaluation theory", Journal of Personality and Social Psychology, 45(4), 1983, pp. 736-750.
[40] Sailer, M., J. Hense, H. Mandl, and M. Klevers, "Psychological perspectives on motivation through gamification", Interaction Design and Architecture(s) Journal, 19, 2013, pp. 28-37.

[41] Sailer, M., J.U. Hense, S.K. Mayr, and H. Mandl, "How gamification motivates: An experimental study of the effects of specific game design elements on psychological need satisfaction", Computers in Human Behavior, 69, 2017, pp. 371-380.

[42] Sailer, M. and L. Homner, "The Gamification of Learning: a Meta-analysis", Educational Psychology Review, 32(1), 2020, pp. 77-112.

[43] Schmid, A., P. Melzer, and M. Schoop, "Gamifying Electronic Negotiation Training - A Mixed Method Study of Students' Motivation, Engagement and Learning", in Proceedings of the 28th European Conference on Information Systems (ECIS), An Online AIS Conference, June 15-17, 2020.

[44] Schmid, A. and M. Schoop, "A Framework for Gamified Electronic Negotiation Training", in D.C. Morais, A. Carreras, A.T. de Almeida, and R. Vetschera (eds.), Group Decision and Negotiation - Behavior, Models, and Support: GDN 2019, Springer: Cham, 2019, pp. 207-222.

[45] Schöbel, S., M. Söllner, and A.N. Mishra, "Does the Winner Take it All? Towards an Understanding of why there might be no One-Size-Fits-All Gamification Design", in Proceedings of the 25th European Conference on Information Systems (ECIS), Guimarães, Portugal, June 5-10, 2017, pp. 3102-3114.

[46] Schoop, M., "Support of Complex Electronic Negotiations", in D.M. Kilgour and C. Eden (eds.), Handbook of Group Decision and Negotiation, Springer Science + Business Media B.V: Dordrecht, 2010, pp. 409-423.

[47] Schoop, M., F. Köhne, D. Staskiewicz, M. Voeth, and U. Herbst, "The antecedents of renegotiations in practice-an exploratory analysis", Group Decision and Negotiation, 17(2), 2008, pp. 127-139.

[48] Seaborn, K. and D.I. Fels, "Gamification in theory and action: A survey", International Journal of Human-Computer Studies, 74, 2015, pp. 14-31.

[49] Stevens, J., Applied Multivariate Statistics for the Social Sciences, 5th edn., Routledge, New York, NY, 2009.

[50] Thompson, L., "The influence of experience on negotiation performance", Journal of Experimental Social Psychology, 26(6), 1990, pp. 528-544.

[51] Tripp, T.M. and H. Sondak, "An Evaluation of Dependent Variables in Experimental Negotiation Studies: Impasse Rates and Pareto Efficiency", Organizational Behavior and Human Decision Processes, 51(2), 1992, pp. 273-295.

[52] Xi, N. and J. Hamari, "Does gamification satisfy needs? A study on the relationship between gamification features and intrinsic need satisfaction", International Journal of Information Management, 46, 2019, pp. 210-221. 